\title{
Colorectal cancer mortality trends in Serbia during 1991-2010: an age-period-cohort analysis and a joinpoint regression analysis
}

Milena $\mathrm{Iic}^{1 *}$ and Irena $\mathrm{Ilic}^{2}$

\begin{abstract}
Background: For both men and women worldwide, colorectal cancer is among the leading causes of cancer-related death. This study aimed to assess the mortality trends of colorectal cancer in Serbia between 1991 and 2010, prior to the introduction of population-based screening.

Methods: Joinpoint regression analysis was used to estimate average annual percent change (AAPC) with the corresponding 95\% confidence interval $(\mathrm{Cl})$. Furthermore, age-period-cohort analysis was performed to examine the effects of birth cohort and calendar period on the observed temporal trends.

Results: We observed a significantly increased trend in colorectal cancer mortality in Serbia during the study period $(\mathrm{AAPC}=1.6 \%, 95 \% \mathrm{Cl} 1.3 \%-1.8 \%)$. Colorectal cancer showed an increased mortality trend in both men (AAPC $=2.0 \%$, $95 \% \mathrm{Cl} 1.7 \%-2.2 \%$ ) and women (AAPC $=1.0 \%, 95 \% \mathrm{Cl} 0.6 \%-1.4 \%$ ). The temporal trend of colorectal cancer mortality was significantly affected by birth cohort $(P<0.05)$, whereas the study period did not significantly affect the trend $(P=0.072)$. Colorectal cancer mortality increased for the first several birth cohorts in Serbia (from 1916 to 1955), followed by downward flexion for people born after the 1960s. According to comparability test, overall mortality trends for colon cancer and rectal and anal cancer were not parallel (the final selected model rejected parallelism, $P<0.05$ ).

Conclusions: We found that colorectal cancer mortality in Serbia increased considerably over the past two decades. Mortality increased particularly in men, but the trends were different according to age group and subsite. In Serbia, interventions to reduce colorectal cancer burden, especially the implementation of a national screening program, as well as treatment improvements and measures to encourage the adoption of a healthy lifestyle, are needed.
\end{abstract}

Keywords: Colorectal cancer, Mortality, Trend, Joinpoint regression analysis

\section{Background}

It is estimated that colorectal cancer causes over 600,000 deaths worldwide annually, accounting for $7.6 \%$ of cancer-related deaths among men and $8.6 \%$ among women; this makes colorectal cancer the fourth most common cause of cancer-related death [1-3]. Although the number of deaths from colorectal cancer is almost the same

\footnotetext{
*Correspondence: drmilenailic@yahoo.com

${ }^{1}$ Department of Epidemiology, Faculty of Medical Sciences,

University of Kragujevac, S. Markovica 69, Kragujevac 34000, Serbia

Full list of author information is available at the end of the article
}

in both developed and developing regions, the death rates vary by more than five times around the world [3]. According to the GLOBOCAN 2008 estimates, the highest colorectal cancer mortalities in both sexes were found in Central and Eastern Europe (20.3 per 100,000 for men, 12.1 per 100,000 for women); the lowest mortalities in both sexes were found in Middle Africa (3.5 per 100,000 and 2.7 per 100,000 , respectively) [1-3].

During the last decade of the twentieth century, colorectal cancer mortality declined steeply in more developed regions: western and northern European countries (the United Kingdom, France, and Sweden), countries 
in North America (the United States of America and Canada), and Australia [3, 4]. At the beginning of the twenty-first century, declines were also observed in Japan, Germany, and Italy [5, 6]. In contrast, most countries in Eastern Europe (such as Russia and Romania) and Southern Europe (such as Portugal and Spain) saw a steep increase in colorectal cancer mortality; however, this was not the case in all countries (e.g., the Czech Republic, Hungary, and Slovakia) [3-5]. Trends were particularly favorable in young people (under 50 years of age), especially in young women [6]. The decreasing mortality trend for colorectal cancer in developed countries after 1990 may be attributable to the implementation of screening programs and improvements in treatment $[7,8]$. More recent screening programs implemented in some European countries probably have had some effect on colorectal cancer mortality $[9,10]$; recent socio-economic changes may have also had a role in reducing colorectal cancer incidence and mortality [11].

Most patients who died of colorectal cancer were aged 50 years or older $[3,6,12]$. Colorectal cancer mortality was 1-2 times higher for men than for women [6]. The etiology of colorectal cancer has not been entirely elucidated, but older age, inflammatory bowel disease, family history, dietary factors, obesity, low physical activity, alcohol consumption, and tobacco smoking have been recognized as risk factors for colorectal cancer [13, 14].

The purpose of this study was to assess temporal changes in colorectal cancer mortality in Serbia between 1991 and 2010, prior to the introduction of populationbased screening.

\section{Methods}

\section{Data sources}

Colorectal cancer was defined according to the International Classification of Diseases (ICD) as malignant neoplasm of the colon (ICD-9 code 153 and ICD-10 code C18) and malignant neoplasm of the rectum, rectosigmoid junction, and anus (ICD-9 code 154 and ICD-10 codes C19-21). Mortality data were obtained from the Statistical Office of the Republic of Serbia (unpublished data). This analysis comprised the entire population of the Republic of Serbia (all ages), during the period 19912010, excluding the Autonomous Province of Kosovo and Metohia, for which data have been unavailable since 1998. Data on the population and composition of the Republic of Serbia (approximately 7.5 million people) by sex and age were obtained from the population censuses in 1991 and 2002; for inter-census years, estimates published by the Statistical Office of the Republic of Serbia were used [15]. In Europe, Serbia had the largest number of internally displaced people and refugees (nearly 400,000 people) during the period 1991-2010; these data were included in the Serbian population and could not be set aside as a special contingent. This study was approved by the Ethics Committee of the Faculty of Medical Sciences, University of Kragujevac (protocol: 01-4801).

\section{Statistical analysis}

We calculated three types of death rates (per 100,000 people): crude, age- and sex-specific, and age-standardized. The age-standardized rate (ASR) was calculated by direct method (Segi's world population was used as standard population, stratified by 10 -year age groups) [16]. To obtain the number of deaths expected in the standard population, the specific rates that were observed in Serbia were applied on the standard population using direct method of standardization. The standardized rate in Serbia was calculated by dividing the expected number of deaths in the standard population by the total standard population. The rates, with number of cases, were given for the beginning and the end of the study period for several age groups (30-34, 35-39, ..., and 75-79).

Trends in colorectal cancer mortality were assessed using joinpoint regression analysis (Joinpoint Regression Software, Version 4.0.4-May 2013; Statistical Methodology and Applications Branch, Surveillance Research Program of the US National Cancer Institute; Bethesda, MD, USA) according to the method proposed by Kim et al. [17]. Lerman's Grid Search Method [18] was used to create a fine grid of all possible locations for joinpoints specified by the settings and to determine the sum of squared error at each one. The Grid Search Method was used to fit the segmented line regression where the joinpoint estimates occur at discrete grid points and to determine the best fit for each individual model. The program started with a minimum of zero joinpoint and was tested to determine whether one or more joinpoints were statistically significant (up to the maximum of five joinpoints that were allowed for each model). The Monte Carlo Permutation method with 4499 replicates was used to test significance. Once the line segments were fortified, the annual percent change (APC) was used to describe the trends in the model. In ASRs of colorectal cancer mortality (1991-2010), trends are presented as average annual percentage changes (AAPCs), which are a summary measure over a fixed interval [19]. For each estimate of APC, 95\% confidence intervals (CIs) were calculated and used to determine if the APC for each segment differed significantly from zero. Also, we assessed pairwise differences using a comparability test to determine whether the two segmented line regression functions were parallel (test of parallelism) or whether the two mean functions were identical (test of coincidence) [20]. Two-sided $P$ values less than 0.05 were considered statistically significant. Joinpoint results were not shown for the subgroups 
of deceased people younger than 30 years because fewer than five deaths from colorectal cancer occurred in each 5 -year age group in any year. We conducted separate analyses for cancer of the colon and the rectum and anus. We analyzed mortalities for men and women separately to account for sex-related differences in the natural history. Given the small number of deceased people younger than 30 years, we limited our analysis to those aged $30-79$.

Additionally, using the United States National Cancer Institute statistical web tool according to the method proposed by Rosenberg et al. [21], we conducted an ageperiod-cohort analysis to examine the effects of birth cohort and calendar period on the observed temporal trends. For age-period-cohort analysis, we used the colorectal cancer mortality data stratified by 5 -year age groups (30-34, 35-39, ... and 75-79); 5-year intervals were also used for calendar periods (1991-1995, 1996$2000, \ldots$, and 2006-2010) and birth cohorts (1916-1920, 1921-1925, ..., and 1976-1980). The central age group, period, and birth cohort were defined as the reference. The degrees of freedom counted the number of free parameters included in each test. The age-period-cohort analysis summarized the deviations from linearity for age, period, and cohort. A marked deviation from zero may indicate the presence of a cohort effect (nonlinearity of period and age effects). The age-period-cohort parameter, called the local drifts, is the APC (with two-tailed 95\% CIs) of the expected age-specific rates over time. APC analysis was used to estimate the net drift parameter, which represents the net sum of the log-linear temporal trend arising from period effects and birth cohort effects. The $1-d f$ Wald test was used to determine significance. $P$ values less than 0.05 were considered statistically significant.

\section{Results}

In Serbia during the period 1991-2010, nearly 42,000 people died of colorectal cancer; the average annual ASR was 14.2 per 100,000 people (Table 1). The average ASR of colorectal cancer mortality was higher in men (18.3 per 100,000) than in women (11.0 per 100,000).

During the study period, we observed a significant trend of increase in colorectal cancer mortality $(\mathrm{AAPC}=1.6 \%, 95 \%$ CI $1.3 \%-1.8 \%$; Fig. 1$)$. The colorectal cancer mortality trend increased in both men $(\mathrm{AAPC}=2.0 \%, 95 \% \mathrm{CI} 1.7 \%-2.2 \%)$ and women (AAPC $=1.0 \%, 95 \%$ CI 0.6\%-1.4\%; Fig. 2). The comparability test showed that the colorectal cancer mortality trends in men and women were not parallel (the final selected model rejected parallelism, $P<0.05$ ).

In our study, the ASRs of people aged 50 years and older were 10-25 times higher than those of people in younger
Table 1 Colorectal cancer mortality in Serbia during the period 1991-2010: number of deaths, crude rate, and agestandardized rate (ASR)

\begin{tabular}{|c|c|c|c|}
\hline Year & No. of deaths & Crude rate & $\mathrm{ASR}^{\mathrm{a}}$ \\
\hline 1991 & 1478 & 19.5 & 11.9 \\
\hline 1992 & 1619 & 21.3 & 12.7 \\
\hline 1993 & 1621 & 21.3 & 12.6 \\
\hline 1994 & 1646 & 21.6 & 12.4 \\
\hline 1995 & 1724 & 22.6 & 12.7 \\
\hline 1996 & 1858 & 24.4 & 13.6 \\
\hline 1997 & 1903 & 25.0 & 13.8 \\
\hline 1998 & 1969 & 26.0 & 13.9 \\
\hline 1999 & 1950 & 25.9 & 13.6 \\
\hline 2000 & 2072 & 27.6 & 14.2 \\
\hline 2001 & 2004 & 26.7 & 13.6 \\
\hline 2002 & 2180 & 29.1 & 14.6 \\
\hline 2003 & 2147 & 28.7 & 14.2 \\
\hline 2004 & 2282 & 30.6 & 14.9 \\
\hline 2005 & 2485 & 33.4 & 16.1 \\
\hline 2006 & 2422 & 32.7 & 15.5 \\
\hline 2007 & 2402 & 32.5 & 15.0 \\
\hline 2008 & 2560 & 34.8 & 16.1 \\
\hline 2009 & 2649 & 36.2 & 16.4 \\
\hline 2010 & 2573 & 35.2 & 15.9 \\
\hline Total & 41,544 & 27.8 & 14.2 \\
\hline
\end{tabular}

a ASR was calculated by using Segi's world standard population. All rates in this table are presented as the number of deaths per 100,000 people

age groups (Table 2). Trends in age-specific mortality for colorectal cancer showed a significant increase for people aged 50 years and older (by 1.6, 2.1, 1.8, 1.5, 1.6, and 1.9\% per year, respectively), whereas for people in younger age groups, non-significant changes were observed. Joinpoint analysis did not identify any joinpoint for the trend in any age group.

Age-period-cohort analysis showed deviations from linearity for all three factors: age, period, and cohort (Table 3). These measures tended to distribute around approximately zero. A slight deviation from zero was observed for people born in the 1956-1960 cohort. In the Serbian population, the risk of death from colorectal cancer increased monotonically for people aged $30-79$ years (Fig. 3). The local drift values were above zero in all of the oldest age groups (50-79 years), although a few insignificant exceptions were observed in the youngest age groups (30-39 years). The period effects remained relatively stable but were elevated in the most recent period (2001-2010). Colorectal cancer mortality increased for the first several birth cohorts, followed by downward flexion for people born after the 1960s. The local drifts were not statistically significant (Wald test $=7.943$, $d f=10, P=0.634$ ). Wald tests showed statistically 

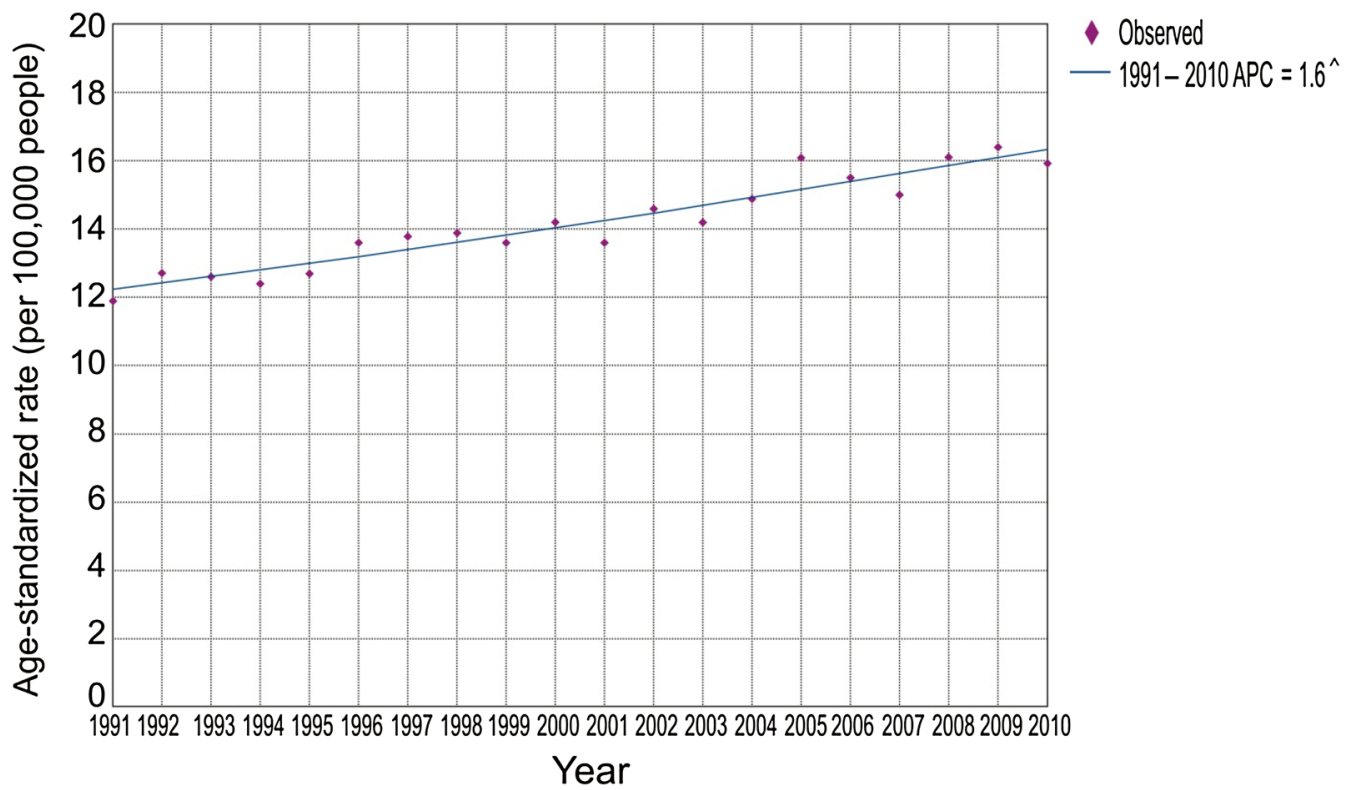

Fig. 1 Trend in mortality of colorectal cancer in Serbia during the period 1991-2010: a joinpoint regression analysis. ^Statistically significant trend, $A P C$ average percentage change

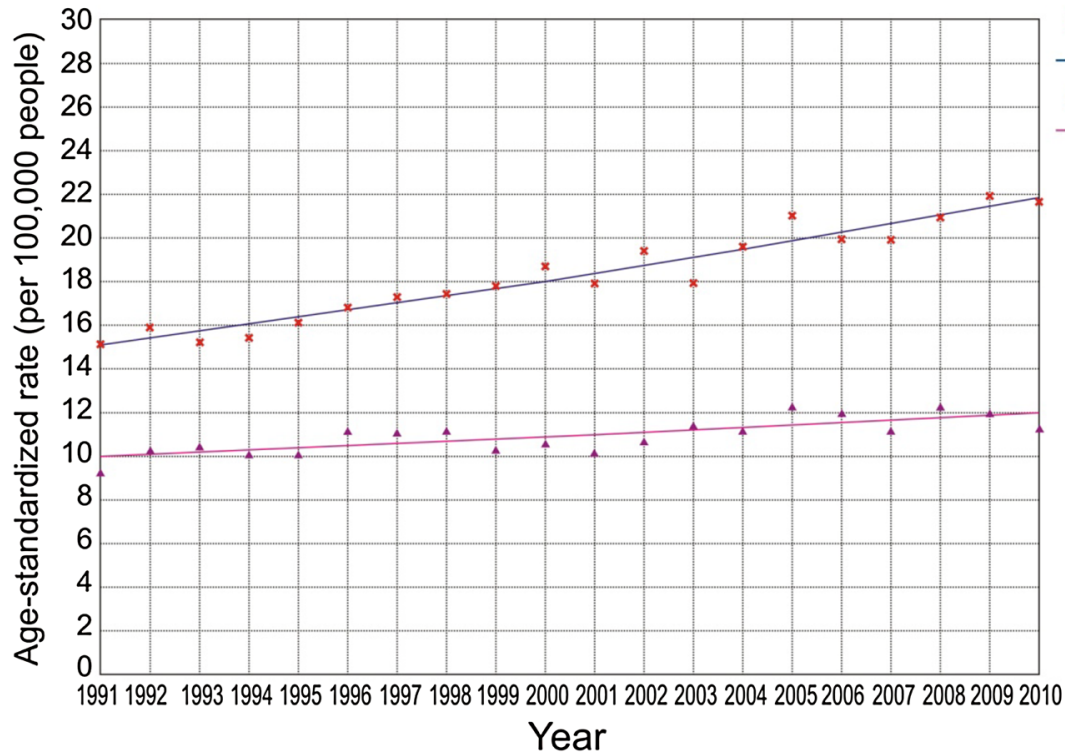

$x$ Men

- 1991-2010APC $=2.0^{\wedge}$

A Women

- 1991-2010APC $=1.06^{\wedge}$

\section{Year}

Fig. 2 Trend in mortality of colorectal cancer in Serbia, by sex, during the period 1991-2010: a joinpoint regression analysis. ^Statistically significant trend, $A P C$ average percentage change

significant cohort effects $(P<0.001)$ and non-significant period effects $(P=0.072)$.

During the period 1991-2010 in Serbia, in men, overall mortality of colon cancer has been significantly increasing (by $2.6 \%$ per year), similar to that of rectal and anal cancer (by $1.4 \%$ per year), as shown in Tables 4 and 5 . During the same period in Serbia, colon cancer mortality for women overall increased by $1.7 \%$ per year, but no significant changes for rectal and anal cancer mortality were observed (AAPC $=0.2 \%$ ). In people of either sex who were 50 years of age or older, a significant increase in colon cancer mortality was observed. For men aged 50 years and above, rectal and anal cancer mortality significantly increased. For women in all age groups, no 
Table 2 Joinpoint regression analysis of colorectal cancer mortality in Serbia (by age) during the period 1991-2010, with data for the beginning and the end of the study period

\begin{tabular}{|c|c|c|c|c|c|c|c|}
\hline \multirow[t]{2}{*}{ Age (years) ${ }^{a}$} & \multirow{2}{*}{$\begin{array}{l}\text { Average annual } \\
\text { age-specific rate }\end{array}$} & \multicolumn{2}{|l|}{ Year 1991} & \multicolumn{2}{|l|}{ Year 2010} & \multirow[t]{2}{*}{ AAPC } & \multirow[t]{2}{*}{$95 \% \mathrm{Cl}$} \\
\hline & & No. of deaths & Mortality $^{\mathbf{b}}$ & No. of deaths & Mortality $^{\mathbf{b}}$ & & \\
\hline $30-34$ & 1.50 & 2 & 0.37 & 12 & 1.73 & 0.1 & -4.3 to 4.8 \\
\hline $35-39$ & 2.84 & 31 & 4.85 & 16 & 3.25 & -1.0 & -2.8 to 0.9 \\
\hline $40-44$ & 6.28 & 36 & 6.19 & 33 & 6.96 & 0.3 & -1.2 to 1.8 \\
\hline $45-49$ & 11.72 & 46 & 11.04 & 55 & 11.13 & 0.0 & -1.2 to 1.3 \\
\hline $50-54$ & 20.70 & 87 & 16.93 & 128 & 24.13 & $1.6^{c}$ & 0.9 to 2.4 \\
\hline $55-59$ & 34.26 & 147 & 25.90 & 230 & 39.58 & $2.1^{c}$ & 1.6 to 2.7 \\
\hline $60-64$ & 56.88 & 223 & 42.40 & 286 & 61.34 & $1.8^{c}$ & 1.4 to 2.3 \\
\hline $65-69$ & 83.46 & 293 & 72.45 & 329 & 98.91 & $1.5^{c}$ & 1.1 to 1.9 \\
\hline $70-74$ & 120.96 & 190 & 96.10 & 451 & 128.23 & $1.6^{c}$ & 1.2 to 2.1 \\
\hline $75-79$ & 154.77 & 192 & 128.53 & 539 & 185.59 & $1.9^{c}$ & 1.4 to 2.4 \\
\hline
\end{tabular}

$A A P C$ average annual percentage change, $\mathrm{Cl}$ confidence interval

a Joinpoint results are not shown for the subgroups of deceased people younger than 30 years because fewer than five colorectal cancer deaths occurred in each

5 -year age group in any year

b All the rates are presented as number of deaths per 100,000 people

c Statistically significant trend

Table 3 Age, period, and cohort effects on colorectal cancer mortality in Serbia during 1991-2010

\begin{tabular}{lccl}
\hline Group & Effect & Deviation & 95\% Confidence interval \\
\hline Age & $30-34$ & -0.115 & -0.410 to 0.180 \\
& $35-39$ & -0.181 & -0.412 to 0.051 \\
& $40-44$ & 0.011 & -0.177 to 0.198 \\
& $45-49$ & 0.099 & -0.057 to 0.255 \\
& $50-54$ & 0.115 & -0.013 to 0.243 \\
& $55-59$ & 0.155 & 0.056 to 0.253 \\
Period & $60-64$ & 0.176 & 0.106 to 0.246 \\
& $65-69$ & 0.068 & 0.012 to 0.124 \\
& $70-74$ & -0.048 & -0.116 to 0.021 \\
& $75-79$ & -0.280 & -0.380 to -0.180 \\
& $1991-1995$ & -0.009 & -0.036 to 0.018 \\
& $1996-2000$ & 0.017 & -0.024 to 0.059 \\
& $2001-2005$ & -0.009 & -0.047 to 0.029 \\
& $2006-2010$ & 0.000 & -0.026 to 0.026 \\
& $1916-1920$ & -0.169 & -0.367 to 0.029 \\
$1921-1925$ & -0.095 & -0.216 to 0.027 \\
& $1926-1930$ & -0.063 & -0.146 to 0.020 \\
$1931-1935$ & -0.043 & -0.101 to 0.014 \\
$1936-1940$ & 0.001 & -0.058 to 0.060 \\
$1941-1945$ & 0.043 & -0.038 to 0.125 \\
$1946-1950$ & 0.063 & -0.045 to 0.172 \\
$1951-1955$ & 0.123 & -0.006 to 0.252 \\
$1956-1960$ & 0.196 & 0.043 to 0.348 \\
& $1961-1965$ & -0.039 & -0.228 to 0.150 \\
& $1976-1970$ & -0.002 & -0.261 to 0.256 \\
& & -0.162 & -0.572 to 0.248 \\
& 1980 & -0.499 & -1.290 to 0.292 \\
\hline & &
\end{tabular}

significant changes for rectal and anal cancer mortality were observed. According to the comparability test, overall mortality trends for colon cancer and rectal and anal cancer were parallel (the final selected model failed reject parallelism, $P=0.279$ ).

\section{Discussion}

The colorectal cancer mortality in Serbia increased considerably over the past two decades. Mortality increased particularly in men, but the trends were different according to age group and subsite. The increased colon cancer mortality among younger men is particularly worrisome. The exceptions were women, in whom no significant trend in rectal and anal cancer mortality was observed.

Worldwide in 2010, Hungary had the highest colorectal cancer mortalities for both men and women (31.1 per 100,000 men and 16.1 per 100,000 women); Georgia and Egypt had the lowest mortalities for both sexes (approximately 2.1 per 100,000 men and 1.6 per 100,000 women) [3]. Serbia was among the countries with high colorectal cancer mortality; other countries with high mortality included the Russian Federation, Poland, Portugal, Slovenia, and the Czech Republic. Except in only a few countries (Kuwait, Cuba, and Qatar), the colorectal cancer mortality was higher for men than for women [3]. The large geographic differences in the global distribution of colorectal cancer are generally difficult to explain [6]. The high mortality across central and eastern European countries, as well as in Serbia and some Mediterranean countries, likely reflects fundamental changes that occurred during the transition period since the 1980s [22]. These 

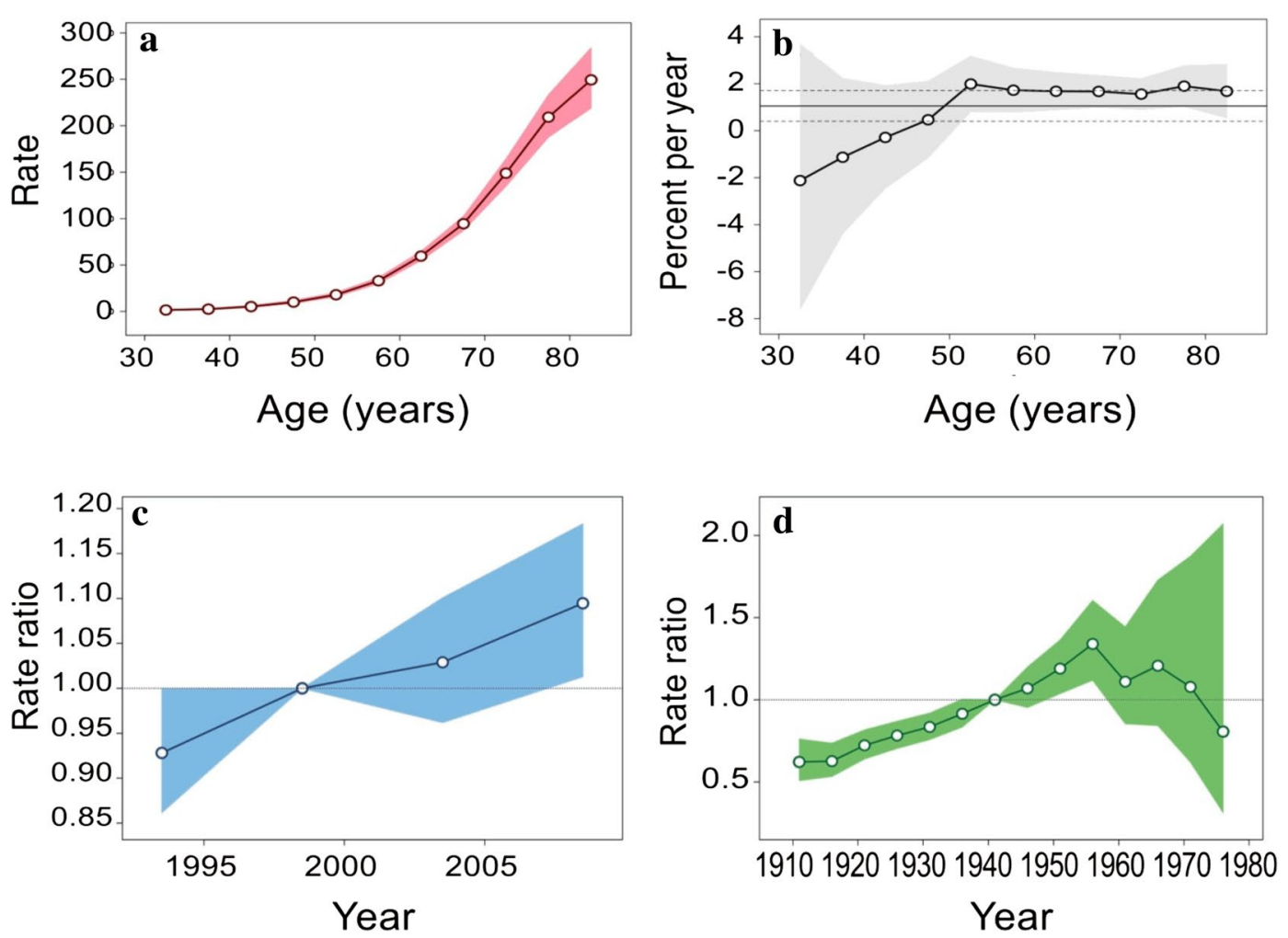

Fig. 3 Mortality of colorectal cancer in Serbia during the period 1991-2010: an age-period-cohort analysis. a Longitudinal age curves of colorectal cancer mortalities: longitudinal age curves of the mortalities (per 100,000 people) of colorectal cancer and the corresponding 95\% confidence intervals (the area colored in pink). b Local drift values for colorectal cancer mortalities: age group-specific annual percent change (\%) in the mortalities of colorectal cancer and the corresponding 95\% confidence intervals (the area colored in grey). c Period effects on colorectal cancer mortalities: period effects obtained from age-period-cohort analyses for the mortalities of colorectal cancer and the corresponding $95 \%$ confidence intervals (the area colored in blue). d Cohort effects on colorectal cancer mortalities: cohort effects obtained from age-period-cohort analyses for the mortalities of colorectal cancer and the corresponding 95\% confidence intervals (the area colored in green)

high mortalities are most likely the result of increased risk factors associated with "westernization," such as increased animal fat and red meat consumption, low vegetable intake, obesity, physical inactivity, tobacco use, and alcohol consumption, which, in the past few decades, characterized newly economically developed countries $[5,10]$. In our study, we found that colorectal cancer mortality increased markedly with age in the cohort of people born between 1956 and 1960. This finding must be interpreted carefully, though, because these cohort values are based on fewer deaths (i.e., lower ASRs). However, since trends in birth cohort effects usually reflect risk factor trends, this increase seems to indicate an increasing colorectal cancer risk in this cohort. During this 1991-2010 period (after the separation from the Eastern Bloc), Serbia sought to accelerate economic development, urbanization, and industrialization, which led to changes in lifestyle and dietary structure. Social circumstances in Serbia were further affected by a devastating economic crisis, which was exacerbated by United Nations sanctions, civil wars in the former Yugoslavia (1991-1995), hundreds of thousands of refugees, the collapse of the dinar, the inability to purchase needed medications, the deterioration of public health, and the bombing of Serbia (1999), as well as post-2000 changes during democratization [23, 24]. In addition, the mortality partly reflects varying data quality worldwide [25].

During the last decade, the colorectal cancer mortalities for both men and women annually declined in the United States (by 2.9\% per year for all races) [4] and in most countries of Western and Northern Europe (in Germany by $2.0 \%$, France by $1.7 \%$, and the United Kingdom and Italy by $1.5 \%$ per year) [5]. Conversely, the colorectal cancer mortalities for both men and women have shown a continuous annual rise over the last decade in some Eastern and Central European countries, such as Russia (by $0.6 \%$ per year) and Croatia and Serbia (by $1.6 \%$ per year) $[5,26]$. Also, increased trends have been observed 
Table 4 Number of deaths, crude and ASR of colorectal cancer mortality for men and women in Serbia during the period 1991-2010

\begin{tabular}{|c|c|c|c|c|c|c|c|c|c|c|c|c|}
\hline \multirow[t]{3}{*}{ Year } & \multicolumn{6}{|l|}{ Men } & \multicolumn{6}{|l|}{ Women } \\
\hline & \multicolumn{3}{|c|}{ Colon cancer } & \multicolumn{3}{|c|}{ Rectal and anal cancer } & \multicolumn{3}{|c|}{ Colon cancer } & \multicolumn{3}{|c|}{ Rectal and anal cancer } \\
\hline & $\begin{array}{l}\text { No. } \\
\text { of deaths }\end{array}$ & $\begin{array}{l}\text { Crude } \\
\text { rate }\end{array}$ & $\mathrm{ASR}^{\mathrm{a}}$ & $\begin{array}{l}\text { No. } \\
\text { of deaths }\end{array}$ & $\begin{array}{l}\text { Crude } \\
\text { rate }\end{array}$ & $\mathrm{ASR}^{\mathrm{a}}$ & $\begin{array}{l}\text { No. } \\
\text { of deaths }\end{array}$ & $\begin{array}{l}\text { Crude } \\
\text { rate }\end{array}$ & $\mathrm{ASR}^{\mathrm{a}}$ & $\begin{array}{l}\text { No. } \\
\text { of deaths }\end{array}$ & $\begin{array}{l}\text { Crude } \\
\text { rate }\end{array}$ & $\mathrm{ASR}^{\mathrm{a}}$ \\
\hline 1991 & 370 & 10.0 & 6.9 & 452 & 12.2 & 8.2 & 314 & 8.1 & 4.4 & 342 & 8.8 & 4.9 \\
\hline 1992 & 414 & 11.1 & 7.4 & 483 & 13.0 & 8.5 & 348 & 9.0 & 4.9 & 374 & 9.6 & 5.4 \\
\hline 1993 & 390 & 10.5 & 6.9 & 467 & 12.6 & 8.3 & 403 & 10.4 & 5.6 & 361 & 9.3 & 4.9 \\
\hline 1994 & 408 & 11.0 & 7.1 & 489 & 13.1 & 8.3 & 377 & 9.7 & 5.0 & 372 & 9.5 & 5.1 \\
\hline 1995 & 430 & 11.5 & 7.2 & 525 & 14.1 & 8.9 & 383 & 9.8 & 5.0 & 386 & 9.9 & 5.1 \\
\hline 1996 & 471 & 12.7 & 7.8 & 551 & 14.8 & 9.0 & 396 & 10.2 & 5.3 & 440 & 11.3 & 5.9 \\
\hline 1997 & 495 & 13.3 & 8.1 & 560 & 15.1 & 9.2 & 451 & 11.6 & 5.9 & 397 & 10.2 & 5.2 \\
\hline 1998 & 530 & 14.4 & 8.6 & 550 & 14.9 & 8.8 & 448 & 11.5 & 5.7 & 441 & 11.4 & 5.5 \\
\hline 1999 & 526 & 14.3 & 8.2 & 603 & 16.4 & 9.6 & 432 & 11.2 & 5.5 & 389 & 10.0 & 4.8 \\
\hline 2000 & 564 & 15.4 & 8.9 & 638 & 17.5 & 9.8 & 424 & 11.0 & 5.0 & 446 & 11.6 & 5.5 \\
\hline 2001 & 556 & 15.2 & 8.7 & 606 & 16.6 & 9.2 & 411 & 10.7 & 5.0 & 431 & 11.2 & 5.2 \\
\hline 2002 & 626 & 17.2 & 9.8 & 639 & 17.5 & 9.6 & 477 & 12.4 & 5.5 & 438 & 11.4 & 5.2 \\
\hline 2003 & 564 & 15.5 & 8.5 & 617 & 17.0 & 9.4 & 470 & 12.2 & 5.5 & 496 & 12.9 & 5.9 \\
\hline 2004 & 660 & 18.2 & 9.8 & 651 & 17.9 & 9.8 & 543 & 14.2 & 6.2 & 428 & 11.2 & 5.0 \\
\hline 2005 & 688 & 19.0 & 10.2 & 719 & 19.9 & 10.8 & 601 & 15.7 & 6.8 & 477 & 12.5 & 5.6 \\
\hline 2006 & 696 & 19.3 & 10.2 & 675 & 18.7 & 9.8 & 562 & 14.8 & 6.5 & 489 & 12.8 & 5.5 \\
\hline 2007 & 719 & 20.0 & 10.1 & 673 & 18.8 & 9.8 & 535 & 14.1 & 6.1 & 475 & 12.5 & 5.1 \\
\hline 2008 & 784 & 21.9 & 11.1 & 680 & 19.0 & 9.8 & 608 & 16.1 & 6.9 & 488 & 12.9 & 5.4 \\
\hline 2009 & 781 & 21.9 & 10.8 & 774 & 21.7 & 11.1 & 615 & 16.4 & 6.6 & 479 & 12.7 & 5.4 \\
\hline 2010 & 753 & 21.2 & 10.6 & 778 & 21.9 & 11.0 & 565 & 15.1 & 6.1 & 477 & 12.7 & 5.2 \\
\hline Overall & 11,425 & 15.7 & 8.8 & 12,130 & 16.6 & 9.4 & 9363 & 12.2 & 5.7 & 8626 & 11.2 & 5.3 \\
\hline
\end{tabular}

${ }^{a}$ ASR was calculated by using Segi's world standard population. All rates in this table are presented as the number of deaths per 100,000 people

in some Central and South American countries (e.g., Mexico and Brazil) [27]. On the other hand, in Slovakia and Slovenia the colorectal cancer mortalities were very high, but they remained constant for both men and women in the last decade [6]. In most countries, colorectal cancer mortality trends for both men and women were more favorable in young people (aged under 50 years) [6]. In Spain, Poland, and Hungary, during the period 19702007, particularly favorable colorectal cancer mortality trends were observed in women in all age groups compared to men [6]. The decrease in colorectal cancer mortality in the United States and Western Europe (e.g., the United Kingdom and France) could be attributed to longterm screening programs and improvements in treatment protocols, as well as to positive lifestyle changes [7-9]. In some Eastern European countries, the benefits, however, of short-term colorectal cancer screening, improvements in treatment, and recent positive changes in dietary and lifestyle habits are still only estimated [9-11, 28]. The promising colorectal cancer mortality trends in women and young people may reflect recent positive changes in diet and lifestyle habits (such as reduced alcohol drinking and tobacco smoking), which have been recommended as cancer prevention measures [11,29].

In Serbia, the lack of decline in colorectal cancer mortality indicates suboptimal levels of cancer control. In 2013, a national program for the early detection of colorectal cancer was implemented. Countrywide data are not yet available, but a single-institution analysis found that the 5-year overall survival rate was $57.8 \%$ in patients younger than 40 and $28.5 \%$ in patients over 65 years of age [30]. For patients with colorectal cancer in Europe, EUROCARE-4 study investigators reported a 5-year relative survival rate of $53.8 \%$; in this study, the highest survival rates were observed in the Nordic and Central European countries, and the lowest survival rates were observed in Eastern Europe [31]. In central Serbia during the period 1999-2008, colorectal cancer incidence was high and showed an increasing trend $[22,25]$. The analysis of disease burden in Serbia showed that, for colorectal cancer, the harmful effects of physical inactivity were higher in women than in men $(31.0 \%$ vs. $20.6 \%$ of total 
Table 5 Joinpoint regression analysis of age-specific mortality rates of colorectal cancer in Serbia, by sex, in the period 1991-2010

\begin{tabular}{|c|c|c|c|c|}
\hline \multirow[t]{2}{*}{$\mathrm{Age}^{\mathrm{a}}$} & \multicolumn{2}{|c|}{ Colon cancer } & \multicolumn{2}{|c|}{ Rectal and anal cancer } \\
\hline & AAPC & $95 \% \mathrm{Cl}$ & AAPC & $95 \% \mathrm{Cl}$ \\
\hline \multicolumn{5}{|l|}{ Men } \\
\hline $30-34$ & $-\mathrm{b}$ & $-b$ & $--^{b}$ & $-b$ \\
\hline $35-39$ & $-b$ & $-b$ & -3.3 & -8.5 to 2.1 \\
\hline $40-44$ & $2.7^{c}$ & 0.3 to 5.1 & -1.2 & -4.5 to 2.3 \\
\hline $45-49$ & -1.2 & -3.5 to 1.2 & 0.6 & -1.0 to 2.3 \\
\hline $50-54$ & $2.8^{c}$ & 1.4 to 4.3 & 1.5 & -0.2 to 3.2 \\
\hline $55-59$ & $3.1^{c}$ & 2.1 to 4.1 & $2.1^{c}$ & 1.2 to 3.1 \\
\hline $60-64$ & $3.1^{c}$ & 2.1 to 4.2 & $2.0^{c}$ & 1.3 to 2.7 \\
\hline $65-69$ & $2.5^{c}$ & 1.7 to 3.3 & $1.5^{\mathrm{c}}$ & 0.7 to 2.2 \\
\hline $70-74$ & $2.9^{c}$ & 2.0 to 3.8 & 0.7 & -0.1 to 1.4 \\
\hline $75-79$ & $2.9^{c}$ & 1.9 to 3.8 & $1.8^{\mathrm{c}}$ & 0.6 to 3.0 \\
\hline All men & $2.6^{c}$ & 2.2 to 3.0 & $1.4^{c}$ & 1.1 to 1.7 \\
\hline \multicolumn{5}{|l|}{ Women } \\
\hline $30-34$ & $--^{b}$ & $-{ }^{b}$ & $-{ }^{\mathrm{b}}$ & $-{ }^{b}$ \\
\hline $35-39$ & 1.7 & -2.4 to 6.0 & $-{ }^{\mathrm{b}}$ & $-{ }^{b}$ \\
\hline $40-44$ & -0.8 & -4.2 to 2.7 & -0.1 & -3.0 to 2.9 \\
\hline $45-49$ & -0.2 & -2.3 to 1.8 & 1.2 & -1.6 to 4.0 \\
\hline $50-54$ & $2.3^{c}$ & 0.4 to 4.3 & 0.1 & -1.9 to 2.2 \\
\hline $55-59$ & $2.4^{c}$ & 0.5 to 4.4 & 0.3 & -0.8 to 1.4 \\
\hline $60-64$ & $2.2^{c}$ & 1.3 to 3.1 & -0.7 & -1.9 to 0.5 \\
\hline $65-69$ & $1.4^{c}$ & 0.5 to 2.4 & -0.1 & -0.8 to 0.7 \\
\hline $70-74$ & $1.6^{c}$ & 0.8 to 2.5 & 0.6 & -0.2 to 1.5 \\
\hline $75-79$ & $1.7^{c}$ & 0.8 to 2.7 & 1.0 & -0.1 to 2.2 \\
\hline All women & $1.7^{c}$ & 1.1 to 2.3 & 0.2 & -0.2 to 0.7 \\
\hline
\end{tabular}

$A A P C$ average annual percentage change, $\mathrm{Cl}$ confidence interval

a Joinpoint results are not shown for the subgroups of deceased people younger than 30 years, because fewer than five colorectal cancer deaths occurred in each 5-year age group in any year

b Joinpoint analysis was not possible, because there were no colorectal cancer deaths in at least one year during the observed period

c Statistically significant trend

disability-adjusted life years [DALY]), as were the harmful effects of being overweight $(16.3 \%$ vs. $13.1 \%$ of total DALY) [32]. The 2006 National Health Survey found that, in Serbia, $54.5 \%$ of people were overweight, subdivided as $18.3 \%$ obese and $36.2 \%$ pre-obese [33]. This survey also found that the average body mass index (BMI) of Serbians older than 20 years was $26.7 \mathrm{~kg} / \mathrm{m}^{2}$ (27.4 for men and 26.0 for women); this represented a substantial increase over 2000, when the average BMI was 26.0. In 2006, nearly one-third of the employed population of Serbia (31.1\%) had a sedentary type of work; this, too, represented a substantial increase over 2000, when the figure was only $25.2 \%$. Also, more than two-thirds of Serbian people $(67.7 \%)$ spent their free time mainly in a sedentary manner. In 2006 in Serbia, smoking was more prevalent in men $(38.1 \%)$ than in women $(29.9 \%)$. On average, men drank four times more alcohol than women ( 8.5 vs. 2.0 drinks per week) [33]. Similarly, in 30 European countries, the level of exposure to underlying lifestyle cancer risk factors corresponds to the pattern of cancer incidence [34]. In the present study, different time trends in mortality for both sexes and for subsites in the Serbian population suggest that colorectal cancer has, at least in part, different etiological factors. Furthermore, the possibility that proximal colon cancers differ from distal colon cancers in terms of biology or carcinogenesis could be an explanation for some variations between countries in the epidemiological and clinical peculiarities of colorectal cancer, as well as differences in cancer detection, treatment, and survival $[35,36]$.

A strength of our study is that it provides the first nationwide estimates of colorectal cancer mortality in Serbia in last two decades. Another strength is that it is a population-based study that used high-quality cancer data with temporal trends analyzed by both joinpoint and age-period-cohort analysis. Also, this high-quality data (including a comprehensive, countrywide death registration system in Serbia) enabled us to make comparisons with other countries [25,37]. Regarding causes of death in Serbia, the World Health Organization (WHO) assessed the quality of data as moderate [37]. For example, for the most recent year (2012), the percentage of unknown and ill-defined cancer deaths in Serbia was $3.8 \%$, which the WHO considered as moderate quality [25]. Contrary to the trends in many countries, the colorectal cancer mortality in Serbia is increasing. Because of this rising mortality trend in Serbia, more effective cancer prevention measures (such as measures focusing on diet and the control of healthy weight, tobacco use, and alcohol consumption), more effective treatments for colorectal cancer, and more effective cancer screening programs focusing on early diagnosis are needed.

Our study did have several limitations. First, we acknowledge that a longer study period may have enabled us to better assess mortality trends, but in Serbia no data were available for this. Second, no separate data exist on colorectal cancer deaths among refugees that can possibly confound the colorectal cancer pattern in Serbia. Clearly, a higher-quality death registration system, which is available in wealthier countries, is needed in Serbia. Third, during the study period, two different revisions of the ICD were used for cancer coding. Fourth, no data are available on colorectal cancer incidence for the entire Republic of Serbia, which limited our ability to explain the increasing mortality trends. Fifth, we had no reliable data on colorectal cancer therapy in Serbia during the study period. The available literature does not have enough relevant information concerning colorectal 
cancer risk factors in the Serbian population. Fecal occult blood testing has been recommended as a national colorectal cancer screening test since only 2013. Therefore, the incompleteness of colorectal cancer screening data in Serbia, which could be used to explain mortality trends, is a limitation of our study. Future studies should investigate whether patterns of risk factors are present in some age cohorts. The colorectal cancer mortality in Serbia contributes to its ranking among countries with the highest mortality. Increasing trends in the colorectal cancer mortality indicate that improved primary and secondary prevention measures, which target young men, particularly, are needed. Reduction in the burden of colorectal cancer in Serbia will require the implementation of a comprehensive national screening program.

\section{Authors' contributions}

Ml conceived of and designed the study and took part in data collection, data analysis, interpretation of the results, and manuscript preparation and review. II took part in data collection, data analysis, interpretation of the results, and manuscript review. Both authors read and approved the final manuscript.

\section{Author details}

${ }^{1}$ Department of Epidemiology, Faculty of Medical Sciences, University of Kragujevac, S. Markovica 69, Kragujevac 34000, Serbia. ${ }^{2}$ Faculty of Medical Sciences, University of Kragujevac, S. Markovica 69, Kragujevac 34000, Serbia.

\section{Acknowledgements}

This work was supported by the Ministry of Education and Science of the Republic of Serbia (Contract No. 175042).

\section{Competing interests}

The authors declare that they have no competing interests.

Received: 17 August 2015 Accepted: 30 May 2016

Published online: 22 June 2016

\section{References}

1. Ferlay J, Shin HR, Bray F, Forman D, Mathers C, Parkin DM. Estimates of worldwide burden of cancer in 2008: gLOBOCAN 2008. Int J Cancer. 2010;127:2893-917.

2. Jemal A, Bray F, Center MM, Ferlay J, Ward E, Forman D. Global cancer statistics. CA Cancer J Clin. 2011;61:69-90.

3. Ferlay J, Soerjomataram I, Ervik M, Dikshit R, Eser S, Mathers C, et al. GLOBOCAN 2012 v1.0, Cancer Incidence and Mortality Worldwide: IARC CancerBase No. 11. Lyon: International Agency for Research on Cancer; 2013.

4. Howlader N, Noone AM, Krapcho M, Neyman N, Aminou R, Altekruse SF, et al., editors. SEER Cancer Statistics Review, 1975-2010. National Cancer Institute: Bethesda; 2013.

5. Matsuda T, Zhang M. Comparison of time trends in colorectal cancer mortality (1990-2006) in the world, from the WHO mortality database. Jpn J Clin Oncol. 2009;39(11):777-8.

6. Bosetti C, Levi F, Rosato V, Bertuccio P, Lucchini F, Negri E, et al. Recent trends in colorectal cancer mortality in Europe. Int J Cancer. 2011;129(1):180-91.

7. Mandel JS, Bond JH, Church TR, Snover DC, Bradley GM, Schuman LM, et al. Reducing mortality from colorectal cancer by screening for fecal occult blood. Minnesota Colon Cancer Control Study. N Engl J Med. 1993;328(19):1365-71.

8. Mellas N, Benbrahim Z, El Mesbahi O. Colorectal cancer: new developments after the 2013 ECCO/ESMO congress. Chin J Cancer. 2014;33(4):218-21.
9. Edwards BK, Ward E, Kohler BA, Eheman C, Zauber AG, Anderson RN, et al. Annual report to the nation on the status of cancer, 1975-2006, featuring colorectal cancer trends and impact of interventions (risk factors, screening, and treatment) to reduce future rates. Cancer. 2010;116(3):544-73.

10. West NJ, Boustière C, Fischbach W, Parente F, Leicester RJ. Colorectal cancer screening in Europe: differences in approach; similar barriers to overcome. Int J Colorectal Dis. 2009:24:731-40.

11. Zavoral M, Suchanek S, Majek O, Fric P, Minarikova P, Minarik M, et al. Colorectal cancer screening: 20 years of development and recent progress. World J Gastroenterol. 2014;20:3825-34.

12. Saika K, Machii R. Time trends in colon, rectum and anus cancer mortality between 1955 and 2008 in Japan, USA and Europe based on the WHO mortality database. Jpn J Clin Oncol. 2011;41(9):1153.

13. Johnson CM, Wei C, Ensor JE, Smolenski DJ, Amos Cl, Levin B, et al. Meta-analyses of colorectal cancer risk factors. Cancer Causes Control. 2013;24(6):1207-22.

14. Fedirko V, Tramacere I, Bagnardi V, Rota M, Scotti L, Islami F, et al. Alcohol drinking and colorectal cancer risk: an overall and dose-response metaanalysis of published studies. Ann Oncol. 2011;22(9):1958-72.

15. Statistical Office of the Republic of Serbia. Demographic Yearbook in the Republic of Serbia, 1991-2010. Belgrade: Statistical Office of the Republic of Serbia; 2011.

16. Jensen OM, Parkin DM, Lennan R, Muir CS, Skeet RG. Cancer registration. Principles and methods. Lyon: International Agency for Research on Cancer; 1991

17. Kim HJ, Fay MP, Feuer EJ, Midthune DN. Permutation tests for joinpoint regression with applications to cancer rates. Stat Med. 2000;19:335-51.

18. Lerman PM. Fitting segmented regression models by grid search. J R Stat Soc Ser C Appl Stat. 1980;29:77-84. doi:10.2307/2346413.

19. Clegg LX, Hankey BF, Tiwari R, Feuer EJ, Edwards BK. Estimating average annual per cent change in trend analysis. Stat Med. 2009;28:3670-82.

20. Kim HJ, Fay MP, Yu B, Barrett MJ, Feuer EJ. Comparability of segmented line regression models. Biometrics. 2004;60:1005-14.

21. Rosenberg PS, Check DP, Anderson WF. A web tool for age-period-cohort analysis of cancer incidence and mortality rates. Cancer Epidemiol Biomarkers Prev. 2014;23:2296-302.

22. Znaor A, van den Hurk C, Primic-Zakelj M, Agius D, Coza D, Demetriou A, et al. Cancer incidence and mortality patterns in South Eastern Europe in the last decade: gaps persist compared with the rest of Europe. Eur J Cancer. 2013:49(7):1683-91.

23. The Impact of UN Security Council Sanctions on the Health of the Population of FR Yugoslavia. Belgrade: Federal Ministry for Labour, Health and Social Policy, Federal Institute for Public Health; 1993.

24. Kunitz SJ. The making and breaking of Yugoslavia and its impact on health. Am J Public Health. 2004;94:1894-904.

25. Ferlay J, Steliarova-Foucher E, Lortet-Tieulent J, Rosso S, Coebergh JW, Comber $\mathrm{H}$, et al. Cancer incidence and mortality patterns in Europe: estimates for 40 countries in 2012. Eur J Cancer. 2013;49:1374-403.

26. Kirac I, Sekerija M, Simunović I, Zgaga L, Velimir Vrdoljak D, Kovacević $D$, et al. Incidence and mortality trends of gastric and colorectal cancers in Croatia, 1988-2008. Croat Med J. 2012:53(2):124-34.

27. Center MM, Jemal A, Smith RA, Ward E. Worldwide variations in colorectal cancer. CA Cancer J Clin. 2009:59:366-78.

28. Giordano L, Bisanti L, Salamina G, Ancelle Park R, Sancho-Garnier H, Espinas J, et al. Euromed Cancer working group. The EUROMED CANCER network: state-of-art of cancer screening programmes in non-EU Mediterranean countries. Eur J Public Health. 2016;26(1):83-9.

29. Boyle P, Autier P, Bartelink H, Baselga J, Boffetta P, Burn J, et al. European Code Against Cancer and scientific justification: third version (2003). Ann Oncol. 2003;14(7):973-1005.

30. Josifovski J, Stojanović S, Radocević-Jelić L, Josifovski T. Localization, clinical and pathological characteristics and survival in sporadic colon cancer patients younger than 40 and over 65 years of age. J Buon. 2004;9(4):403-8.

31. Berrino F, De Angelis R, Sant M, Rosso S, Bielska-Lasota M, Coebergh JW, et al. EUROCARE Working group. Survival for eight major cancers and all cancers combined for European adults diagnosed in 1995-99: results of the EUROCARE-4 study. Lancet Oncol. 2007;8(9):773-83.

32. Sipetić S, Bjegović-Mikanović V, Vlajinac H, Marinković J, Janković S, Terzić $Z$, et al. The burden of disease preventable by risk factor reduction in Serbia. Vojnosanit Pregl. 2013;70:445-51. 
33. Ministry of Health, Republic of Serbia. National Health survey, Serbia 2006. Belgrade: Ministry of Health; 2007.

34. Boniol M, Autier P. Prevalence of main cancer lifestyle risk factors in Europe in 2000. Eur J Cancer. 2010;46:2534-44.

35. Deng G, Kakar S, Tanaka H, Matsuzaki K, Miura S, Sleisenger MH, et al. Proximal and distal colorectal cancers show distinct gene-specific methylation profiles and clinical and molecular characteristics. Eur J Cancer. 2008;44:1290-301.
36. Phipps Al, Lindor NM, Jenkins MA, Baron JA, Win AK, Gallinger S, et al. Colon and rectal cancer survival by tumor location and microsatellite instability: the Colon Cancer Family Registry. Dis Colon Rectum. 2013;56(8):937-44.

37. Mathers CD, Ma Fat D, Inoue M, Rao C, Lopez A. Counting the dead and what they died from: an assessement of the global statusof cause death data. Bull World Health Org. 2005:83:171-7.

\section{Submit your next manuscript to BioMed Central and we will help you at every step:}

- We accept pre-submission inquiries

- Our selector tool helps you to find the most relevant journal

- We provide round the clock customer support

- Convenient online submission

- Thorough peer review

- Inclusion in PubMed and all major indexing services

- Maximum visibility for your research

Submit your manuscript at

www.biomedcentral.com/submit 